that the demonstration of validity is more difficult than reliability, no evidence or discussion of this is presented. Thus, the reader must take somewhat on faith the suggestions offered with only anecdotal and an occasional experimental study offered in support of the constructs discussed. Obviously, the onus for this is not the authors' alone, but more recognition of the pre-scientific status of interviewing should be made more explicit in Kahn and Cannell's book.

\title{
William Coleman
}

System Development Corporation

Social Relations and Morale in Small Groups, by Eric F. Gardner and George G. Thompson. New York: Appleton-Century-Crofts, 1956. ix $+312 \mathrm{pp}$.

This book presents the results of four years of intensive psychometric research on fraternities at Syracuse University. The major goal of this research was to develop more flexible and theoretically sounder methods of assessing group structure, group effectiveness, and morale. The results are quite impressive, and the book should prove to be a gold mine of techniques to any theoretical or applied psychologist who wishes to study small groups.

Traditional psychometry has largely ignored the implications of the fact that a man will choose as his friends people whom he feels have the capacity for satisfying his psychological needs. Since his needs will vary from time to time, a man will typically have a circle of friends some of whom he will approach at one time and some at another. It would seem logical, therefore, to place a man's acquaintances on a number of different scales according to their potential for satisfying the different needs he may have. The authors have done this for four important needs (affiliation, playmirth, succorance, achievement-recognition); they found that the respondents ranked their fraternity brothers differently when considering their potentialities for the satisfaction of these different needs.

Another major drawback of traditional sociometric methods has been the weakness of the scales generated ... the typical technique permits only the ranking of an individual in relation to the other members of his group. Besides preventing the use of interval scale statistical techniques, this makes it impossible to compare social groups on the basis of the average strength of ingroup ties. In an attempt to construct an equal interval scale with comparability between individuals (and therefore between fraternities), the authors required the respondents to rate their fraternity brothers with reference to "all males you have ever known" on a scale of eight subjectively equal intervals. The authors then averaged ratings given to fraternity brothers, ratings received from fraternity brothers, and so forth, and 
were thus able to define a host of "social relations" variables which distinguished the fraternities in their ability to provide for their members' social needs.

In addition, a number of very interesting techniques were developed and validated for the measurement of esprit de corps morale and group effectiveness.

In contrast to the exciting advances in methodology, the major theoretical findings of the study are rather mundane. A typical finding is that groups which satisfy the needs of their members have higher morale and are more effective in attaining their goals. This is an old story and is presented with little theoretical elaboration. Somewhat more interesting is the observation that members of more cohesive fraternities are less active in outside groups. But there is no attempt to find out why this is true. All of this is only to suggest that the authors now move to a more microscopic investigation in an attempt to discover the forces behind the conditions which they have measured so well.

\section{Dean G. Pruitt}

University of Michigan

Clinical and Counseling Psychology, by John M. Hadley. New York: Alfred A. Knopf, 1958. Pp. vii $+682+$ xix.

John M. Hadley, the author of Clinical and Counseling Psychology is a clinical psychologist. He received his doctorate degree from Iowa in 1939. At the present time, he is located at Purdue University where he serves the dual role of Director of the Psychological Clinic and Director of Graduate Training in Clinical Psychology. This volume has grown out of Hadley's clinical experience. The sections on clinical practice are excellent and authoritative; the sections on theory and statistics are less adequate.

The book is directed to the college senior or graduate student familiar with psychological terminology and literature. It is characterized by a serious approach to the subject matter and is not aimed at appealing to the general public. There are, for example, no illustrations in the 682 pages of text. The format itself prescribes a textbook for studying and not simply for reading. This is not to suggest that the writing is unnecessarily abstruse or polysyllabic. On the contrary, Dr. Hadley writes in a clear and interesting style. Throughout the text principles are illustrated by appropriate case histories and examples. Liberal use is made of sub-chapter headings which should prove helpful when the student reviews the material. At the end of each chapter is a summary paragraph and a relevant bibliography. In addition, the text includes name and subject indices as well as a glossary of psychological terms. 